\title{
(+)-TSUGACETAL, A LIGNAN ACETAL FROM TAIWAN HEMLOCK
}

\author{
Jim-Min Fang, Kuo-Min Wei, Yu-Shia Cheng*, Ming-Chu Cheng and Yu Wang \\ Department of Chemistry, National Taiwan University, Taipei, Taiwan, Republic of China
}

(Revised received 14 October 1984)

Key Word Index-Tsuga chinensis var. formosana; Taiwan hemlock; lignan acetal; tsugacetal; X-ray crystal structure.

\begin{abstract}
By the evidence of ${ }^{1} \mathrm{H}$ and ${ }^{13} \mathrm{C}$ NMR spectra, and single crystal structure determination, a novel lignan acetal, (+)-tsugacetal, isolated from Tsuga chinensis var. formosana, was found to have an $\alpha$-conidendrin-related structure with an acetal methoxy group at the $\beta$-position.
\end{abstract}

Tsuga chinensis Pritzel var. formosana, known as Taiwan hemlock, is one of the major forest trees indigenous to the high mountain area of Taiwan. The heartwood of the plant is frequently used in building and for paper making. We investigated the chemical constitution of the heartwood and found a novel lignan acetal, 1, namely $(+)$ tsugacetal. The compound was isolated as colourless crystals, mp $188-190^{\circ}$. Its mass spectrum revealed the parent peak at $m / z 372$ and diagnostic peaks at $m / z 341$ and 340 due to the fragmentation of a methoxy group. The formula of tsugacetal (1) was determined as $\mathrm{C}_{21} \mathrm{H}_{24} \mathrm{O}_{6}$ by elemental analysis and the pertinent $M_{r}$. The presence of a phenol moiety was shown in the IR spectrum at 3400 , 1600,1580 and $1500 \mathrm{~cm}^{-1}$, as well as in the UV spectrum $\lambda_{\max } \mathrm{nm}: 212$ and 283 . Analysis of the ${ }^{1} \mathrm{H}$ NMR spectrum revealed that tsugacetal had a lignan acetal structure related to $\alpha$-conidendrin. The resonance of the acetal methoxy group (OMe-9) occurred at $\delta 3.38(\mathrm{~s})$. The resonance of the $C-9$ proton occurred at $\delta 4.99$ as a doublet with a small coupling constant of $4.5 \mathrm{~Hz}$, thus inferring the cis configuration between the $\mathrm{C}-8$ and $\mathrm{C}-9$ protons. The assigned structure of $(+)$-tsugacetal (1) was confirmed by its ${ }^{13} \mathrm{C}$ NMR spectrum and a single-crystal $X$ ray analysis (see below).

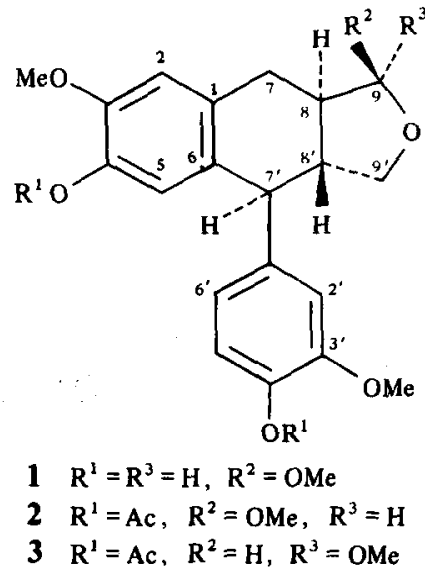

* To whom correspondence should be addressed.
Acetylation of tsugacetal afforded a crystalline diacetate (2), $\mathrm{mp} 87-88^{\circ}$. Its IR spectrum showed absorption for acetyl groups at $1750 \mathrm{~cm}^{-1}$. The ${ }^{1} \mathrm{H}$ NMR spectrum displayed characteristic resonances at $\delta 2.19\left(\mathrm{~s}, \mathrm{O}_{2} \mathrm{CMe}\right)$, $2.27\left(s, \mathrm{O}_{2} \mathrm{CMe}\right)$ and $4.98(d, J=4.5 \mathrm{~Hz}, \mathrm{H}-9)$. The ${ }^{13} \mathrm{C}$ NMR spectrum [1] revealed that the resonances of ortho- and para-carbons in 2 appeared at $\Delta \delta 4.2-8.4$ lower fields, while resonances of ipso carbons occurred at $\Delta \delta 1.4-5.9$ higher fields than those of the corresponding resonances in diol 1 . A significant shielding effect $(\Delta \delta 4.8)$ at C-6 was observed, probably due to the transmission of the substituent effect through the methylene group [2].

It was noted that an acetate derivative of a lignan acetal has been reported [3] to have the structure of tsugacetal diacetate (2). Since a considerable discrepancy of physical properties was found between 2 and the compound previously obtained [3], we investigated the spectroscopic properties of the two compounds [R. C. Cambie personal communication]. It was concluded that the previously obtained compound [3] was actually the C-9 epimer (3) of 2. These two compounds exhibited similar ${ }^{13} \mathrm{C}$ NMR spectra, except that acetal 2 had the C-9 resonance at $\Delta \delta 5.3$ higher field. In the ${ }^{1} \mathrm{H}$ NMR spectra, the $\mathrm{H}-9$ resonance of 2 (at $\delta 4.98$ ) showed a doublet with a smaller coupling constant of $4.5 \mathrm{~Hz}$, while the corresponding resonance of epimer 3 (at $\delta 5.05$ ) gave a doublet with a coupling constant of $5.5 \mathrm{~Hz}$. Structure 2 should have the same configuration as that of tsugacetal (1), because the conformation of the molecule is not to be changed by acetylation. Therefore, 2 has the C-8 and C-9 protons in the cis relationship, while 3 should have the same protons in the trans orientation.

The molecular structure of $(+)$-tsugacetal was determined by $\mathrm{X}$-ray diffraction. Crystal data: $\mathrm{C}_{21} \mathrm{H}_{24} \mathrm{O}_{6}$, monoclinic, space group $\mathrm{P} 2_{1}, a=12.418(2), \quad b$ $=14.465(3), \quad c=5.207(1), \quad Z=2 ; \quad D_{m}=1.30, \quad D_{x}$ $=1.32 \mathrm{~g} / \mathrm{cm}^{3}, 2819$ reflections were measured using MoK $_{a}$ radiation. Refinement of positional and anisotropic thermal parameters for all non-hydrogen atoms converged to $\boldsymbol{R}=0.06$ and $\boldsymbol{R}_{w}=0.05$. Hydrogen atoms of hydroxyl and methoxyl groups are found in the difference Fourier map and the others are calculated assuming the tetrahedral or trigonal environment around carbon atoms. The positional parameters are then refined with the 
non-hydrogen atoms. The positional and thermal parameters are in deposit."

All the bond distances and angles are normal, distances are given in Fig. 1. The dihedral angle between the two benzene rings is $82.7^{\circ}$. The torsional angle between the O-1-C-9 and the C-8-C-8 $8^{\prime}$ bonds is $84.5^{\circ}$. Moreover, taking the plane of C-7-C-8-C-9, the methoxy oxygen atom $(\mathrm{O}-1)$ is $0.57 \AA$ away from the plane and the $\mathrm{C}-8$ atom is on the same side of the plane but at a distance of $1.28 \mathrm{~A}$. Because of the tetrahedral configuration around the C-8 and C-9 atoms, it is easy to understand why the two hydrogen atoms at C-8 and C-9 are in the cis configuration. The torsional angle between $\mathrm{C}-\mathrm{H}$ bonds at C-8, C-9 is $41^{\circ}$ for structure 1 with the methoxy oxygen at the $\beta$-position; the corresponding $J_{\mathrm{H}-\mathrm{H}}$ is $4.5 \mathrm{~Hz}$.

\section{EXPERIMENTAL}

Wood of $T$. chinensis var. formosana (Hay.) was collected in the high mountain areas $(2-3 \mathrm{~km})$ of Taiwan. The heartwood was sliced, air-dried $(870 \mathrm{~g})$ and extracted exhaustively with $\mathrm{MeOH}$. The extract was consecutively partitioned with hexane and

* The atomic co-ordinates and thermal parameters for this work are available on request from the Director of the Cambridge Crystallographic Data Centre.
EtOAc. The combined EtOAc extracts were concd and dissolved in $\mathrm{CHCl}_{3}$. The $\mathrm{CHCl}_{3}$-soluble portion $(13 \mathrm{~g})$ was chromatographed on silica gel (EtOAc-hexane, 3:7, $\boldsymbol{R}_{f} 0.14$ ) to afford $0.32 \mathrm{~g}$ tsugacetal 1 as colourless crystals, mp $188-190^{\circ}$ (from EtOH). $\left[\alpha_{\mathrm{D}}^{\top}+68.3^{\circ}\left(\mathrm{Me}_{2} \mathrm{CO} ; c\right.\right.$ 0.93). IR $v_{\max }^{\mathrm{KBr}} \mathrm{cm}^{-1}: 3400,1600$, 1580,1500 . UV $\lambda \lambda_{\max }^{\mathrm{EtOH}}(\varepsilon) \mathrm{nm}: 212$ (15000), 283 (6900). ${ }^{1} \mathrm{H}$ NMR $\left(\mathrm{CDCl}_{3}, 100 \mathrm{MHz}\right) \delta 1.85-3.11\left(4 \mathrm{H}, \mathrm{m}, \mathrm{H}-7, \mathrm{H}-8, \mathrm{H}-8^{\prime}\right), 3.38(3 \mathrm{H}$, $s, \mathrm{OMe}^{-9)}$, 3.45-3.98 (3H, m, H-7', H-9'), 3.78 (3H, s, ArOMe), 3.84 (3H, $s, \mathrm{ArOMe}), 4.99(1 \mathrm{H}, d, J=4.5 \mathrm{~Hz}, \mathrm{H}-9), 5.51(1 \mathrm{H}, s, \mathrm{ArOH})$, $5.65(1 \mathrm{H}, s, \mathrm{ArOH}), 6.34(1 \mathrm{H}, s, \mathrm{H}-5), 6.55(1 \mathrm{H}, \mathrm{s}, \mathrm{H}-2), 6.58(1 \mathrm{H}$ $\left.d d, J=7.8,1.5 \mathrm{~Hz}, \mathrm{H}^{\prime} 6^{\prime}\right), 6.67\left(1 \mathrm{H}, d, J=1.5 \mathrm{~Hz}, \mathrm{H}-2^{\prime}\right), 6.81(1 \mathrm{H}$, $\left.d, J=7.8 \mathrm{~Hz}, \mathrm{H}-5^{\prime}\right) .{ }^{13} \mathrm{C}$ NMR $\left(\mathrm{CDCl}_{3}, \mathrm{TMS}, 25.2 \mathrm{MHz}\right): \delta 29.2$ (C-7), 46.0 (C-8, C-8'), 50.9 (C-7'), 54.9 (acetal OMe), 55.9 (ArOMe), 72.3 (C-9'), 105.0 (C-9), 110.4 (C-2), 111.1 (C-2'), 114.2 (C-5'), 115.0(C-5), $\left.121.5\left(\mathrm{C}^{\prime} 6^{\prime}\right), 127.9(\mathrm{C}-1), 132.6\left(\mathrm{C}^{\prime}\right)^{\prime}\right), 136.2$ (C6), $143.5(C-4), 144.3\left(C-4^{\prime}\right), 145.0(C-3), 146.4$ (C-3'). EIMS $70 \mathrm{eV}$, $m / z$ (rel. int.) $372[\mathrm{M}]^{+}(36), 341$ (14), $340(100), 310$ (27), 216 (27), 137 (22). (Found: $\mathrm{C}, 67.79 ; \mathrm{H}, 6.55$. Calc. for $\mathrm{C}_{21} \mathrm{H}_{24} \mathrm{O}_{6}$ requires: C, $67.77 ; \mathrm{H}, 6.45 \%$.

Tsugacetal was acetylated with $\mathrm{Ac}_{2} \mathrm{O}$ in $\mathrm{C}_{5} \mathrm{H}_{5} \mathrm{~N}$ to afford the crystalline diacetate $2, \mathrm{mp} 87-88^{\circ} .[\alpha]_{\mathrm{D}}+30.9^{\circ}\left(\mathrm{Me}_{2} \mathrm{CO} ; \mathrm{c} 1.0\right)$. IR $v_{\max }^{\mathrm{KBr}} \mathrm{cm}^{-1}: 1750 .{ }^{1} \mathrm{H}$ NMR $\left(\mathrm{CDCl}_{3}\right): \delta 2.19\left(3 \mathrm{H}, s, \mathrm{O}_{2} \mathrm{CMe}\right)$, $2.27\left(3 \mathrm{H}, s, \mathrm{O}_{2} \mathrm{CMe}\right.$ ), 2.27-3.17 (4H, $\left.m, \mathrm{H}-7, \mathrm{H}-8, \mathrm{H}-8^{\prime}\right), 3.37$ (3H, $s$, acetal OMe), 3.42-3.99 (3H, $m$, H-7', H-9'), 3.75 (3H, s, OMe), $3.82(3 \mathrm{H}, s, \mathrm{OMe}), 4.98(1 \mathrm{H}, d, J=4.5 \mathrm{~Hz}, \mathrm{H}-9), 6.46(1 \mathrm{H}, s, \mathrm{H}-5)$, $6.65\left(1 \mathrm{H}, s, \mathrm{H}-2^{\prime}\right), 6.69\left(1 \mathrm{H}, d, J=8 \mathrm{~Hz}, \mathrm{H}-6^{\prime}\right), 6.74(1 \mathrm{H}, s, \mathrm{H}-2)$, $6.95\left(1 \mathrm{H}, d, J=8 \mathrm{~Hz}, \mathrm{H}-5^{\prime}\right) .{ }^{13} \mathrm{CNMR}\left(\mathrm{CDCl}_{3}\right) \delta 20.6$ $\left(\mathrm{CH}_{3} \mathrm{CO}_{2}\right), 29.5(\mathrm{C}-7), 45.7$ (C-8), $46.1\left(\mathrm{C}-8^{\prime}\right), 50.8\left(\mathrm{C}-7^{\prime}\right), 54.8$ (acetal OMe), 55.8 (ArOMe), 71.9 (C-9'), 104.6 (C-9), 111.9 (C-2),

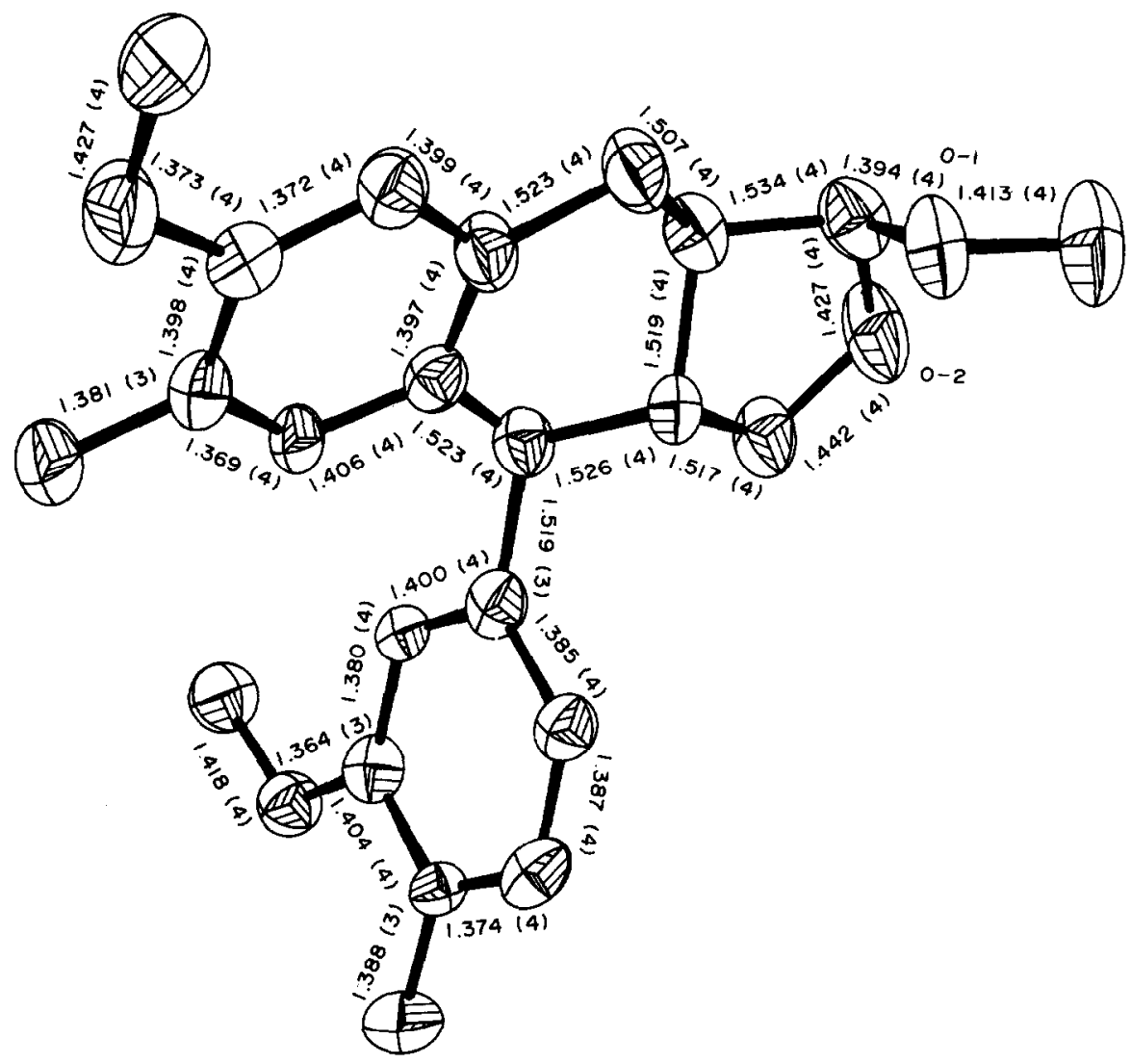

Fig. 1. ORTEP drawing of $(+)$-tsugacetal with $50 \%$ probability of anisotropic thermal ellipsoid. 
112.7 (C-2'), $120.6\left(C^{\prime}-6^{\prime}\right), 122.6$ (C-5'), 123.3 (C-5), 131.4 (C-6), 135.2 (C-1), 137.6 (C-4), 138.4 (C-1'), 142.8 (C-4), 149.2 (C-3), $151.1\left(\mathrm{C}-3^{\prime}\right), 168.6\left(\mathrm{MeCO}_{2}\right)$.

Acknowledgement-We are grateful to the National Science Council (Republic of China) for financial support.

\section{REFERENCES}

1. Fonseca, S. F., Campello, J. P., Barata, L. E. S. and Ruveda, E. A. (1978) Phytochemistry 17, 499.

2. Shapiro, M. J. (1977) Tetrahedron 33, 1091.

3. Cambie, R. C., Parnell, J. C. and Rodrigo, R. (1979) Tetrahedron Letters 1085. 